\title{
1 Long-term warming amplifies shifts in the carbon cycle of experimental ponds
}

2

5 1. Environment and Sustainability Institute, University of Exeter, Penryn, Cornwall, TR10 9EZ. U.K.

6 2. School of Biological \& Chemical Sciences, Queen Mary University of London, London E1 4NS, UK.

7 3. Imperial College London, Department of Life Sciences, Silwood Park Campus, Buckhurst Road, Ascot, Berkshire 8 SL5 7PY, UK.

9

10 I denotes equal author contribution

$11{ }^{*}$ Correspondence to: Gabriel Yvon-Durocher (g.yvon-durocher@exeter.ac.uk) or Mark Trimmer

12 (m.trimmer@qmul.ac.uk)

14 Words in abstract: 194

15 Words in main text: 1743

16 Figures: 3

17 Tables: 2 
Lakes and ponds cover only about $4 \%$ of the Earth's non-glaciated surface ${ }^{1}$, yet they

20 represent disproportionately large sources of methane and carbon dioxide ${ }^{2-4}$. Indeed, very small ponds (e.g. $<0.001 \mathrm{~km}^{2}$ ) may account for approximately $40 \%$ of all $\mathrm{CH}_{4}$ emissions from inland waters ${ }^{5}$. Understanding how greenhouse gas (GHG) emissions from aquatic ecosystems will respond to global warming is therefore vital for forecasting biosphere-carbon cycle feedbacks. Here, we present findings on the long-term effects of warming on the fluxes of GHGs and rates of ecosystem metabolism in experimental ponds. We show that shifts in $\mathrm{CH}_{4}$ and $\mathrm{CO}_{2}$ fluxes, and rates of gross primary production (GPP) and ecosystem respiration (Reco), observed in the first year became amplified over seven years of warming. The capacity to absorb $\mathrm{CO}_{2}$ was nearly halved after seven years of warmer conditions. The phenology of GHG fluxes were also altered, with $\mathrm{CO}_{2}$ drawdown and $\mathrm{CH}_{4}$ emissions peaking one month earlier in the warmed treatments. These findings show that warming can fundamentally alter the carbon balance of small ponds over a number of years, reducing their capacity to sequester $\mathrm{CO}_{2}$ and increasing emissions of $\mathrm{CH}_{4}$; such positive feedbacks could ultimately accelerate climate change.

Respiration and methanogenesis respond more strongly to temperature change than photosynthesis ${ }^{6-9}$. Consequently, warming has been shown to increase $\mathrm{CO}_{2}$ and $\mathrm{CH}_{4}$ emissions and reduce carbon sequestration in experimental ponds ${ }^{10-13}$. However, these experiments have either been restricted to relatively short-term responses to warming (e.g. 1 year or less $)^{10,11}$ or have not investigated how the effects of warming change over time ${ }^{13,14}$. Therefore, a key unanswered question for understanding how greenhouse gas dynamics in freshwater ponds will respond to global warming is: do the high temperature sensitivities of methanogenesis and respiration result in increased emissions of $\mathrm{CH}_{4}$ and $\mathrm{CO}_{2}$, and reduced carbon sequestration under warming that is sustained over the long-term, and which could potentially accelerate the rate of climate change? 
term, driven by the exponential temperature dependence of respiration, followed by a damped effect of warming later ${ }^{15-17}$. These diminishing long-term responses have been attributed to loss of labile carbon substrates ${ }^{15}$, physiological acclimation ${ }^{16}$, evolutionary adaptation ${ }^{18}$ or community turnover through ecological dynamics ${ }^{19}$. These findings are important because they imply carbon cycle responses to global warming should be more complex than the simple exponential effect of temperature on respiration rates alone ${ }^{17}$.

Small freshwater ponds contribute disproportionately to greenhouse gas emissions budgets from inland waters ${ }^{5}$. However, whether shifts in the fluxes of $\mathrm{CH}_{4}$ and $\mathrm{CO}_{2}$ observed in short-term warming experiments ${ }^{10,11}$, are sustained in the long-term (e.g. $>1$ year to decadal timescales) in these ecosystems is unknown, which severely limits our ability to predict whether future changes in greenhouse gas fluxes ${ }^{4,5}$ will contribute to accelerating or slowing global warming. We tackled this fundamental knowledge gap using an array of experimental mesocosms that were designed to mimic mid-latitude ponds, to investigate the effects of long-term warming on the ecosystem-level exchange of $\mathrm{CO}_{2}$ and $\mathrm{CH}_{4}$ with the atmosphere. We present a detailed analysis of the seasonal dynamics of the key metabolic and GHG fluxes in the carbon cycle in the sixth (2012) and seventh (2013) year of the experiment, which we contrast with our initial findings from the first year (2007) of warming ${ }^{10,11}$ to explore whether, like terrestrial ecosystems ${ }^{15-17}$, the effects of warming on the carbon cycle in freshwater ponds are dampened in the long-term. $\mathrm{CH}_{4}$ emissions were elevated in the warmed treatments in both 2007 and 2013. However, Table 1; Table 2). Consequently, a generalised additive mixed effects model (GAMM) that included a 'treatment' by 'year' interaction on the intercept provided the best fit to the data (Table 1), demonstrating that the effects of warming on median $\mathrm{CH}_{4}$ emissions were larger in 2013 than 2007. 
71 carbon metabolism. The effect size of warming increased from 1.2- to 1.8-fold for gross primary

72 production (GPP) and 1.4- to 2-fold for ecosystem respiration ( $\mathrm{R}_{\mathrm{eco}}$ ) between 2007 and 2012 (Fig.

73 2a-d; Table 1). Consequently, GAMMs fitted to the seasonal distributions of GPP and Reco and

74 including a 'treatment' by 'year' interaction on the intercept, provided the best fit to the data.

75 Because rates of $\mathrm{R}_{\text {eco }}$ increased more with warming than those of GPP, the $\mathrm{R}_{\text {eco }} / \mathrm{GPP}$ ratio was 1.15-

76 fold higher in the warmed treatments, indicating reduced capacity for carbon sequestration in both

772007 and 2012 (Fig 2e \& f). High frequency measurements of $\mathrm{CO}_{2}$ exchange between the ponds

78 and the atmosphere in 2013 confirmed these findings, with annual net $\mathrm{CO}_{2}$ uptake reduced by $50 \%$

79 in the warmed mesocosms (Fig. 3; Table 1; Table 2). Together these results demonstrate that the

80 effects of warming on the key fluxes in the carbon cycle became amplified over the seven years of

81 the experiment, in stark contrast to the damped effects of long-term warming reported for terrestrial

82 systems ${ }^{15-17}$. So what mechanisms might be responsible for the amplified effects of warming in

83 freshwater ponds?

The experimental mesocosms were seeded in 2005 with organisms and organic matter (see

Methods) and have since been on a trajectory of ecosystem development. Succession theory

proposes that in the early stages of ecosystem development, as organic matter and biomass accumulate, rates of GPP exceed $\mathrm{R}_{\mathrm{eco}}$ and the ratio of $\mathrm{R}_{\mathrm{eco}} / \mathrm{GPP}<1^{20}$. As ecosystems develop towards later successional stages, energy fixed by GPP tends to be balanced by energy consumed 89 through $\mathrm{R}_{\text {eco }}$ (i.e. the ratio of $\mathrm{R}_{\text {eco }} / \mathrm{GPP} \approx 1$ ) and biomass production is maximised ${ }^{20}$. Consistent with ecosystem succession theory, the $\mathrm{R}_{\text {eco }} / \mathrm{GPP}$ ratio and annual totals for GPP and $\mathrm{R}_{\text {eco }}$ all increased substantially over the course of the experiment in both the warmed and ambient treatments, with increases in GPP and $\mathrm{R}_{\text {eco }}$ much larger in the warmed mesocosms (Fig. 2a-d). In line with the data on total carbon metabolism, we also observed consistently higher biomass of macrophytes (Fig S5;

94 Table S3), phytoplankton and zooplankton in the warmed treatments in the long term ${ }^{21}$. Together, 
metabolic fluxes. These results demonstrate that warming can fundamentally alter the energetic balance at the ecosystem level: firstly, because in the short term, rates of respiration rise more sharply with temperature than photosynthesis (increasing $\mathrm{R}_{\mathrm{eco}} / \mathrm{GPP}$ ); and secondly, over the long term, because higher rates of metabolism drive more rapid ecosystem development ${ }^{22}$, magnifying energetic imbalances and shifts in the carbon cycle. Natural ecosystems are typified by far from equilibrium dynamics ${ }^{23}$, and thus, because warming can act both as a stressor and a driver of physiology, understanding the long-term impacts of warming on ecosystem properties requires both an appreciation of the acute effects of temperature change on organism metabolism and subsequent impacts on the successional dynamics of ecosystems.

Focusing on the fluxes of $\mathrm{CO}_{2}$ and $\mathrm{CH}_{4}$ measured in 2013 at a high temporal resolution reveals that, in addition to driving shifts in the annual budgets, long-term warming also profoundly altered the seasonality of $\mathrm{CH}_{4}$ emissions (Fig. 1) and net daily exchange of $\mathrm{CO}_{2}$ (Fig. 3). Rates of net daily $\mathrm{CO}_{2}$ emission (i.e. days where total $\mathrm{CO}_{2}$ emissions $>$ absorption) peaked in October in the warmed treatments, whilst, on average, ambient ponds were net sinks for $\mathrm{CO}_{2}$ over the entire year. By contrast, rates of net daily $\mathrm{CO}_{2}$ absorption (i.e. days where total $\mathrm{CO}_{2}$ absorption $>$ emissions) peaked in the warmed treatments in June, while they peaked in July in the ambient ponds (Fig. 3). These respective peaks in net $\mathrm{CO}_{2}$ absorption coincided with peak $\mathrm{CH}_{4}$ emissions (Fig. 1), implying a strong coupling between $\mathrm{CO}_{2}$ drawdown by photosynthesis and substrate supply for methanogenesis, which is a well-known characteristic of many natural aquatic ecosystems ${ }^{24}$. Indeed, the most marked effects of warming on $\mathrm{CH}_{4}$ emissions occurred during the spring and early summer (Fig. 1). Later in the year, however, the effects were negligible (Fig. 1) when rates of respiration exceeded those of photosynthesis (e.g. $\mathrm{CO}_{2}$ production $>\mathrm{CO}_{2}$ consumption leading to net $\mathrm{CO}_{2}$ emissions; cf Figs $1 \& 3$ ) in the warmed treatments and rates of methanogenesis may have been limited by photosynthetically derived carbon. These results suggest that the effects of global warming could shift the seasonal timing of carbon fluxes, which, in turn, affect the supply and demand of substrates that support aquatic ecosystem productivity. 
Overall, our findings provide the first experimental evidence that the annual balance of greenhouse gas fluxes from freshwater ponds remain profoundly altered at inter-annual timescales, with substantially elevated $\mathrm{CH}_{4}$ emissions and lower $\mathrm{CO}_{2}$ absorption. The extent to which these results are important for understanding how carbon fluxes from globally important pond ecosystems ${ }^{5}$ respond to warming depends on whether carbon dynamics in our experimental mesocosms are broadly representative of those in natural systems. One important distinction between the mesocosms and natural shallow lakes is that they are not embedded within a watershed, and consequently, receive little terrestrially derived organic carbon, which is often an important 131 carbon flux in lakes and ponds ${ }^{25}$. In consequence, carbon cycle dynamics in the mesocosms are driven predominantly by autochthonous production, which could alter sediment characteristics, coupling between photosynthesis and respiration, and GHG emissions compared with natural ponds that receive allochthonous carbon subsidies. To investigate this and assess the relevance of our 135 findings for natural ponds, we measured the carbon $(\mathrm{C})$, nitrogen $(\mathrm{N})$ and $\mathrm{C}: \mathrm{N}$ ratios of the mesocosm sediments (Table 2) and compared them with values from natural lakes and ponds 137 spanning the dystrophic to oligotrophic spectrum ${ }^{25}$. The sediment characteristics of the mesocosms 138 are similar to those from natural oligotrophic lakes ${ }^{26}$. Mean annual rates of gross primary 139 production and ecosystem respiration (Table 2) are also comparable to those from natural lakes ${ }^{5,27}$, 140 indicating that rates of total carbon metabolism reflect those of natural systems. Finally, recent 141 work has shown that the size of lakes and ponds (in terms of surface area) are critical for 142 determining their greenhouse gases (GHG) emissions, with $\mathrm{CH}_{4}$ flux per unit area increasing as a 143 power function of decreasing lake surface area ${ }^{5,28,29}$. Our mesocosms, with a surface area of $3.14 \times$ $14410^{-4}$ ha, fall within the smallest category of ponds analysed in a global synthesis of GHG emissions ${ }^{5}$ 145 and have average $\mathrm{CH}_{4}$ concentrations that are indistinguishable from natural ponds of a similar size 146 (Fig. S4). Taken together, this evidence demonstrates results from our mesocosm experiment are of 147 direct relevance for understanding carbon cycle responses to warming in freshwater ponds. Our results suggest that profound shifts in the carbon fluxes of small ponds should be expected over the 
149 long term in a warming world, which is of particular concern in light of the fact that we are only

150 just beginning to appreciate the importance of such small water bodies in global budgets of GHG

151 emissions from inland waters ${ }^{5,28,29}$.

\section{Acknowledgements}

This study was supported by a grant from the Natural Environment Research Council of the UK (NE/H022511/1) awarded to MT, GY-D \& GW.

\section{Author contributions}

MT and G. Y-D conceived the study. CJH \& G. Y-D conducted the experiments. G. Y-D, CJH and

MT analysed the data. G. Y-D. wrote the manuscript and all authors contributed to revisions. The authors declare no conflict of interest.

\section{Corresponding Authors}

163 Requests for materials should be sent to Gabriel Yvon-Durocher (g.yvon-durocher@exeter.ac.uk) or Mark Trimmer(m.trimmer@qmul.ac.uk).

\section{References}

1. Verpoorter, C., Kutser, T., Seekell, D. A. \& Tranvik, L. J. A global inventory of lakes based on high-resolution satellite imagery. Geophys. Res. Lett. 41, 6396-6402 (2014).

2. Bastviken, D., Tranvik, L. J., Downing, J. A., Crill, P. M. \& Enrich-Prast, A. Freshwater Methane Emissions Offset the Continental Carbon Sink. Science 331, 50-50 (2011).

3. Cole, J. J. et al. Plumbing the global carbon cycle: Integrating inland waters into the terrestrial carbon budget. Ecosystems 10, 171-184 (2007).

4. Wik, M., Varner, R. K., Anthony, K. W., MacIntyre, S. \& Bastviken, D. Climate-sensitive northern lakes and ponds are critical components of methane release. Nature Geoscience $\mathbf{9}$, 99- (2016).

5. Holgerson, M. A. \& Raymond, P. A. Large contribution to inland water $\mathrm{CO} 2$ and $\mathrm{CH} 4$ emissions from very small ponds. Nature Geosci 9, 222-226

6. Yvon-Durocher, G. et al. Reconciling the temperature dependence of respiration across timescales and ecosystem types. Nature 487, 472-476 (2012).

7. Yvon-Durocher, G. et al. Methane fluxes show consistent temperature dependence across microbial to ecosystem scales. Nature 507, 488- (2014).

8. Allen, A. P., Gillooly, J. F. \& Brown, J. H. Linking the global carbon cycle to individual 
metabolism. Functional Ecology 19, 202-213 (2005).

9. Marotta, H. et al. Greenhouse gas production in low-latitude lake sediments responds strongly to warming. Nature Climate Change 4, 467-470 (2014).

10. Yvon-Durocher, G., Jones, J. I., Trimmer, M., Woodward, G. \& Montoya, J. M. Warming alters the metabolic balance of ecosystems. Philosophical Transactions of the Royal Society B - Biological Scienes 365, 2117-2126 (2010).

11. Yvon-Durocher, G., Montoya, J. M., Woodward, G., Jones, J. I. \& Trimmer, M. Warming increases the proportion of primary production emitted as methane from freshwater mesocosms. Global Change Biology 17, 1225-1234 (2011).

12. Atwood, T. B. et al. Warming alters food web-driven changes in the $\mathrm{CO} 2$ flux of experimental pond ecosystems. Biology Letters 11, (2015).

13. Davidson, T. A. et al. Eutrophication effects on greenhouse gas fluxes from shallow-lake mesocosms override those of climate warming. Global Change Biology 21, 4449-4463 (2015).

14. Liboriussen, L. et al. Effects of warming and nutrients on sediment community respiration in shallow lakes: an outdoor mesocosm experiment. Freshwater Biology 56, 437-447 (2010).

15. Melillo, J. M. Soil Warming and Carbon-Cycle Feedbacks to the Climate System. Science 298, 2173-2176 (2002).

16. Luo, Y., Wan, S., Hui, D. \& Wallace, L. Acclimatization of soil respiration to warming in a tall grass prairie. Nature 413, 622-625 (2001).

17. Luo, Y. Terrestrial carbon-cycle feedback to climate warming. Annu. Rev. Ecol. Evol. Syst. (2007).

18. Bradford, M. A., Watts, B. W. \& Davies, C. A. Thermal adaptation of heterotrophic soil respiration in laboratory microcosms. Global Change Biology 16, 1576-1588 (2010).

19. Karhu, K. et al. Temperature sensitivity of soil respiration rates enhanced by microbial community response. Nature 513, 81-(2014).

20. Odum, E. P. The strategy of ecosystem development. Science 164, 262-270 (1969).

21. Yvon-Durocher, G. et al. Five Years of Experimental Warming Increases the Biodiversity and Productivity of Phytoplankton. Plos Biol 13, (2015).

22. Anderson-Teixeira, K. J., Vitousek, P. M. \& Brown, J. H. Amplified temperature dependence in ecosystems developing on the lava flows of Mauna Loa, Hawai'i. P Natl Acad Sci Usa 105, 228-233 (2008).

23. Levin, S. A. Ecosystems and the biosphere as complex adaptive systems. Ecosystems 1, 431436 (1998).

24. Whiting, G. J. \& Chanton, J. P. Primary production control of methane emission from wetlands. Nature 364, 794-795 (1993).

25. Tranvik, L. J. et al. Lakes and reservoirs as regulators of carbon cycling and climate. Limnol. Oceangr. 54, 2298-2314 (2009).

26. Dean, W. E. The carbon cycle and biogeochemical dynamics in lake sediments. Journal of Paeleolimnology 21, 375-393 (1999).

27. Likens, G. E. in Primary Productivity of the Biosphere 14, 185-202 (Springer Berlin Heidelberg, 1975).

28. Kankaala, P., Huotari, J., Tulonen, T. \& Ojala, A. Lake-size dependent physical forcing drives carbon dioxide and methane effluxes from lakes in a boreal landscape. Limnol. Oceangr. 58, 1915-1930 (2013).

29. Bastviken, D., Cole, J., Pace, M. \& Tranvik, L. Methane emissions from lakes: Dependence of lake characteristics, two regional assessments, and a global estimate. Global Biogeochem. Cycles 18, (2004).

30. Dossena, M. et al. Warming alters community size structure and ecosystem functioning. Proceedings of the Royal Society B: Biological Sciences 279, 3011-3019 (2012). 
Table 1| Multi-model selection on generalised additive mixed effects models fitted to the seasonal $\mathrm{CH}_{4}, \mathrm{CO}_{2}$ and metabolic flux data. A range of models testing hypotheses on the effects of the warming treatment ('treat') and the 'year' of the experiment were fitted to the seasonal greenhouse gas and metabolic flux data; 'treat' and 'year' along with their interaction assess differences in median flux values, while comparisons between $s(\mathrm{DOY})$ and $s(\mathrm{DOY}$, by $=$ treat) assess whether the seasonality of flux differs among treatments. Models were compared via the small sample size corrected Akaike Information Criterion (AICc), delta AICc is the difference in AICc score relative to the model with the lowest value (most parsimonious model) and AICc Weight (Wt) is the relative support for the model. The best fitting models were selected as those returning the lowest AICc score and the highest AICc weight and are highlighted in bold.

\begin{tabular}{|c|c|c|c|c|c|}
\hline Model & df & $N$ & $\mathrm{AICc}$ & $\Delta \mathrm{AICc}$ & AICc Wt \\
\hline \multicolumn{6}{|l|}{$\mathrm{CH}_{4}$ Emissions } \\
\hline MEO - fixed $=$ treat $*$ year $+s($ DOY $)$ & 8 & 311 & 961.53 & 0.00 & 0.71 \\
\hline ME $1-$ fixed $=$ treat + year $+s(D O Y)$ & 7 & 311 & 965.47 & 3.94 & 0.16 \\
\hline ME2 - fixed $=$ treat $*$ year $+s(D O Y$, by $=$ treat $)$ & 10 & 311 & 966.03 & 1.51 & 0.13 \\
\hline ME3 - fixed $=$ year + s(DOY $)$ & 6 & 311 & 969.66 & 5.13 & 0.00 \\
\hline $\mathrm{ME} 4-$ fixed $=$ treat $+\mathrm{s}(\mathrm{DOY})$ & 6 & 311 & 996.13 & 31.60 & 0.00 \\
\hline ME3 - fixed = s(DOY $)$ & 5 & 311 & 999.85 & 35.32 & 0.00 \\
\hline \multicolumn{6}{|l|}{$G P P$} \\
\hline GPPO - fixed $=$ treat $*$ year + s(DOY $)$ & 8 & 208 & 243.00 & 0.00 & 0.97 \\
\hline GPP1 - fixed $=$ treat + year + s $($ DOY $)$ & 7 & 208 & 250.58 & 7.59 & 0.02 \\
\hline GPP $2-$ fixed $=$ treat $*$ year $+\mathrm{s}(\mathrm{DOY}$, by $=$ treat $)$ & 10 & 208 & 253.66 & 10.67 & 0.00 \\
\hline GPP3- fixed = year + s(DOY) & 6 & 208 & 255.69 & 12.69 & 0.00 \\
\hline GPP4 - fixed $=$ treat $+s(D O Y)$ & 6 & 208 & 266.18 & 23.19 & 0.00 \\
\hline GPP5 - fixed $=s(D O Y)$ & 5 & 208 & 271.54 & 28.55 & 0.00 \\
\hline \multicolumn{6}{|l|}{$\boldsymbol{R}_{\text {eco }}$} \\
\hline Ro - fixed $=$ treat $*$ year $+s(D O Y)$ & 8 & 208 & 277.11 & 0.00 & 0.82 \\
\hline $\mathrm{R} 1-$ fixed $=$ treat + year $+\mathrm{s}(\mathrm{DOY})$ & 7 & 208 & 280.34 & 3.23 & 0.16 \\
\hline $\mathrm{R} 2-$ fixed $=$ treat $*$ year $+\mathrm{s}(\mathrm{DOY}$, by $=$ treat $)$ & 10 & 208 & 285.33 & 8.22 & 0.01 \\
\hline $\mathrm{R} 3-$ fixed $=$ year $+\mathrm{s}(\mathrm{DOY})$ & 6 & 208 & 293.76 & 16.65 & 0.00 \\
\hline $\mathrm{R} 4-$ fixed $=$ treat $+\mathrm{s}(\mathrm{DOY})$ & 6 & 208 & 315.73 & 38.63 & 0.00 \\
\hline $\mathrm{R} 5-$ fixed $=\mathrm{s}(\mathrm{DOY})$ & 5 & 208 & 327.21 & 50.11 & 0.00 \\
\hline \multicolumn{6}{|l|}{$R_{e c o} / G P P$} \\
\hline RAT0 - fixed $=$ treat + year $+\mathbf{s}($ DOY $)$ & 7 & 208 & 46.14 & $\mathbf{0 . 0 0}$ & 0.81 \\
\hline RAT $1-$ fixed $=$ year + s $($ DOY $)$ & 6 & 208 & 49.90 & 3.76 & 0.12 \\
\hline RAT2 - fixed $=$ treat + year $+s($ DOY $)$ & 8 & 208 & 51.17 & 5.03 & 0.07 \\
\hline RAT3 - fixed $=$ treat $*$ year $+s($ DOY, by $=$ treat $)$ & 10 & 208 & 59.43 & 13.29 & 0.00 \\
\hline RAT4 - fixed $=$ treat $+s($ DOY $)$ & 6 & 208 & 65.17 & 19.03 & 0.00 \\
\hline RAT5 - fixed = s(DOY $)$ & 5 & 208 & 67.37 & 21.23 & 0.00 \\
\hline \multicolumn{6}{|l|}{ Net $\mathrm{CO}_{2}$ Flux - 2013} \\
\hline NEEO - fixed $=$ treat $+s($ DOY, by $=$ treat $)$ & 8 & 4656 & 103884.7 & 0.00 & 1.00 \\
\hline NEE1 - fixed $=s(D O Y$, by $=$ treat $)$ & 7 & 4656 & 103901.5 & 16.79 & 0.00 \\
\hline $\mathrm{NEE} 2-$ fixed $=$ treat $+\mathrm{s}(\mathrm{DOY})$ & 6 & 4656 & 103965.2 & 80.55 & 0.00 \\
\hline NEE3 - fixed $=s(D O Y)$ & 5 & 4656 & 103982.0 & 97.34 & 0.00 \\
\hline
\end{tabular}


Table 2| Annual carbon fluxes and sediment characteristics of the mesocosms.

246

\begin{tabular}{lllllll} 
& \multicolumn{2}{l}{2007} & & \multicolumn{2}{l}{2013} \\
\cline { 2 - 6 } & Ambient & Heated & Ambient & Heated & Ambient & Heated \\
\hline $\mathrm{CH}_{4}$ emissions $\left(\mathrm{g} \mathrm{CH}_{4} \mathrm{~m}^{-2} \mathrm{y}^{-1}\right)$ & $0.20(0.016)$ & $0.27(0.013)$ & - & - & $0.33(0.012)$ & $0.74(0.04)$ \\
$\mathrm{Net} \mathrm{CO}_{2}$ flux $\left(\mathrm{g} \mathrm{C} \mathrm{m}^{-2} \mathrm{y}^{-1}\right)$ & - & - & - & - & $-20.1(6.4)$ & $-10.9(12.3)$ \\
$\mathrm{GPP}\left(\mathrm{g} \mathrm{C} \mathrm{m}^{-2} \mathrm{y}^{-1}\right)$ & $207.1(1.1)$ & $243.7(1.6)$ & $221.9(1.1)$ & $392.1(1.8)$ & - & - \\
$\mathrm{R}_{\mathrm{eco}}\left(\mathrm{g} \mathrm{C} \mathrm{m}^{-2} \mathrm{y}^{-1}\right)$ & $164.3(1.4)$ & $233.2(1.7)$ & $210.3(1.3)$ & $422.9(1.9)$ & - & - \\
$\mathrm{R}_{\mathrm{eco}} / \mathrm{GPP}$ & $0.83(0.06)$ & $0.97(0.09)$ & $1.03(0.1)$ & $1.16(0.20)$ & - & - \\
Sediment \% Carbon & - & - & - & - & $2.9(1.3)$ & $3.7(2.3)$ \\
Sediment \% Nitrogen & - & - & - & - & $0.3(0.1)$ & $0.4(0.3)$ \\
Sediment C:N (molar) & - & - & - & - & $11.8(1.1)$ & $11.1(1.3)$ \\
\hline
\end{tabular}


A

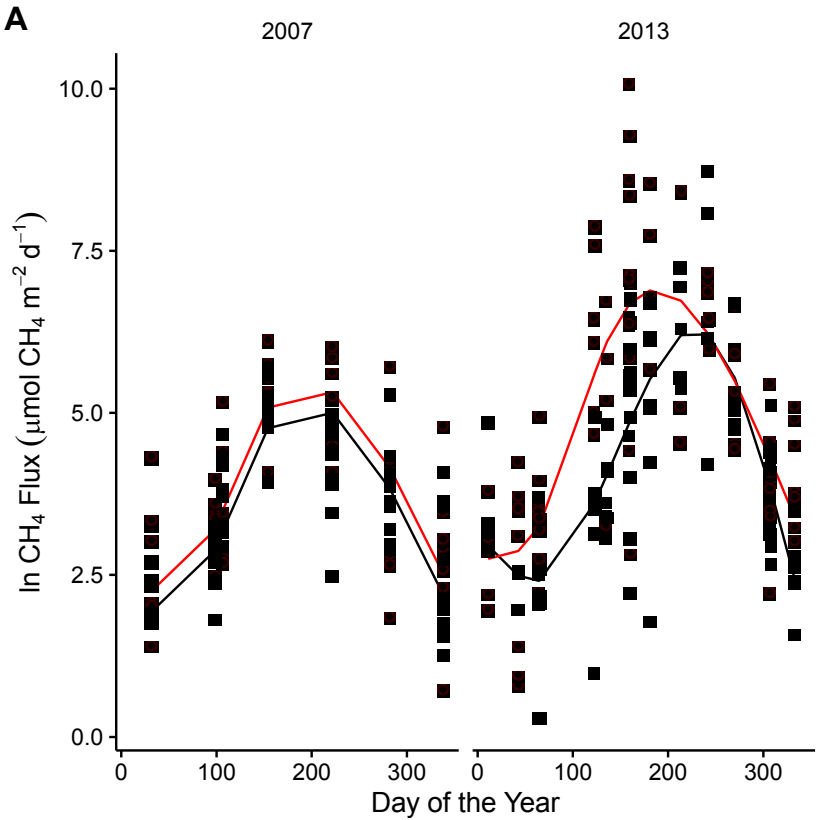

B

2007

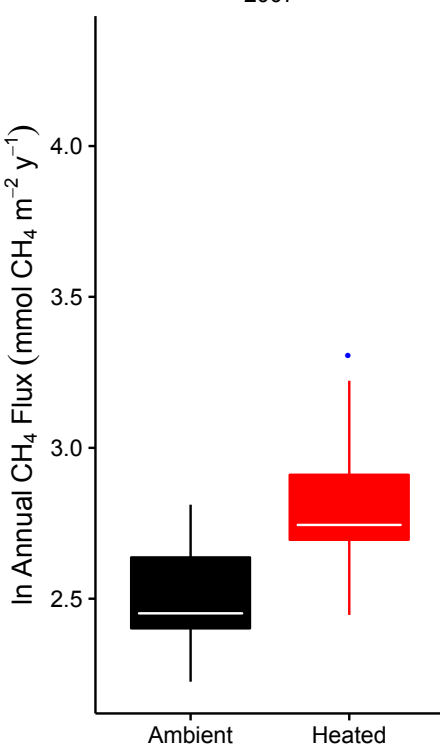

2013

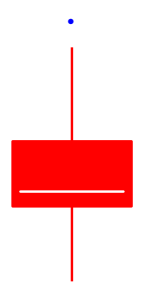

Figure 1| Long-term experimental warming amplifies shifts in $\mathbf{C H}_{4}$ emissions. (a) The seasonal variation in $\mathrm{CH}_{4}$ flux from 2007 and 2013 demonstrate that the effect of warming was larger in 2013 than 2007. (b) Box whisker plots of annual $\mathrm{CH}_{4}$ flux from each pond calculated by integrating the seasonal data over time. These data show that the effect size of warming increased from 1.5 fold in 2007 to 2.5 fold in 2013 highlighting that the effects of warming became amplified in the long term. The solid lines denote the fixed effects from the best fitting GAMM model (see Table 1 for model selection). Red circles and lines denote warmed treatments, while the ambient treatments are in black. Tops and bottoms of boxes in box-whisker plots correspond to the 25th and 75th percentiles, horizontal white lines correspond to medians, whisker extents correspond to $1.5 \mathrm{x}$ the interquartile range and blue points are outliers. 

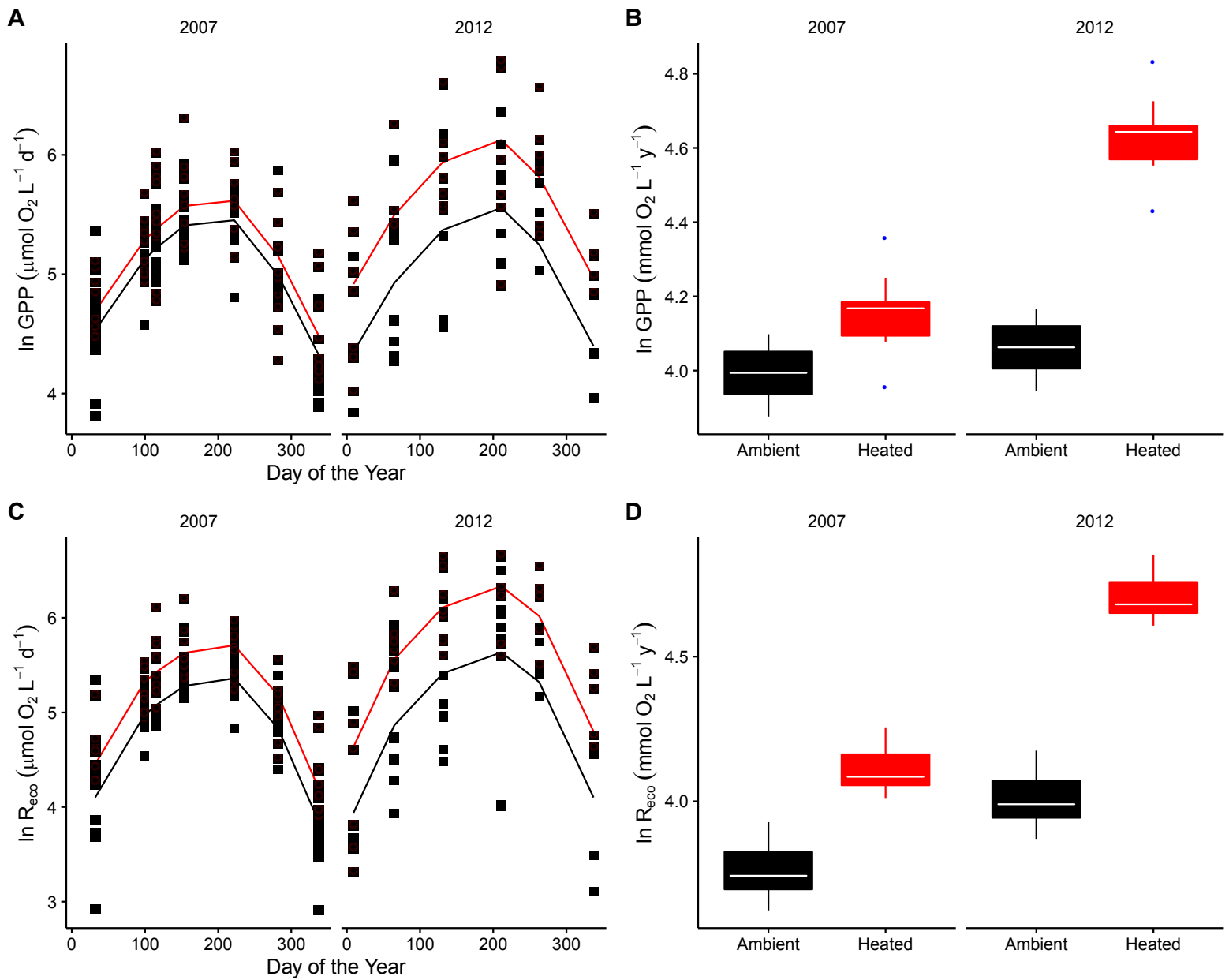

D

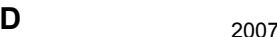

012
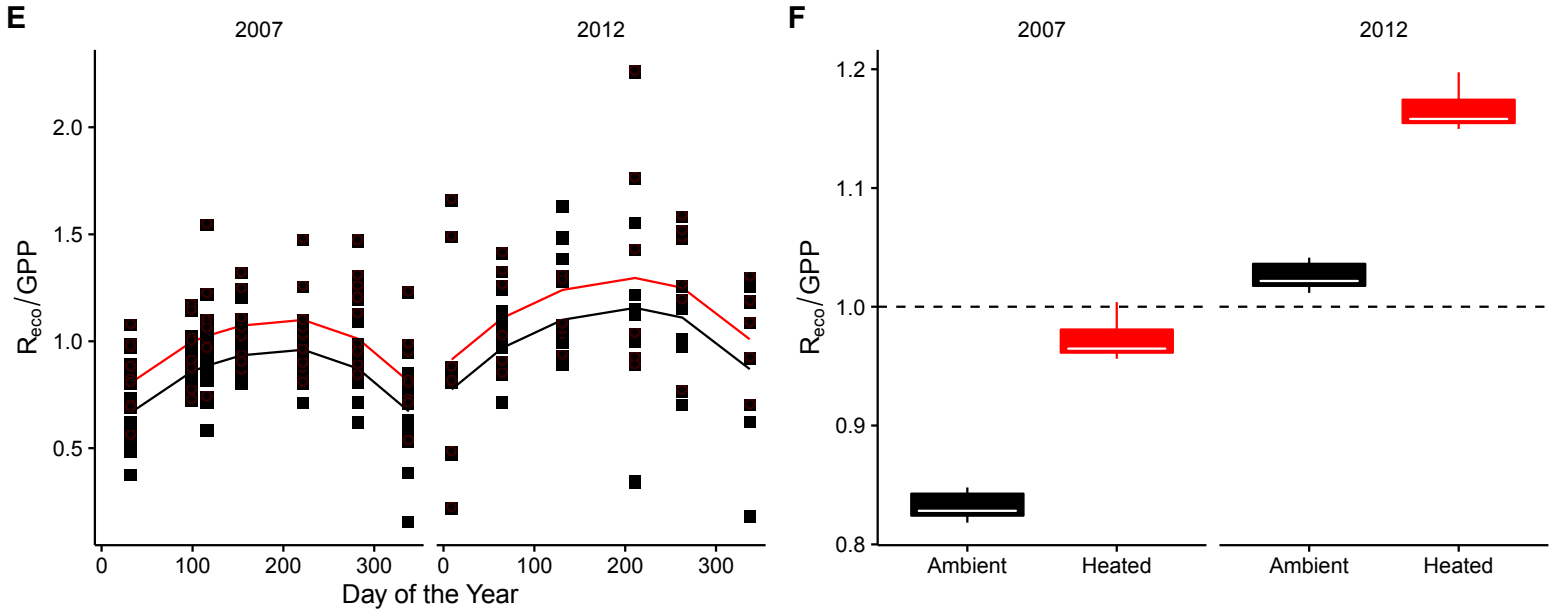

Figure 2| Long-term experimental warming amplifies shifts in ecosystem metabolism. Seasonal distributions of (a) Rates of gross primary production, GPP, (c) ecosystem respiration, $\mathrm{R}_{\mathrm{eco}}$, and (e) the $\mathrm{R}_{\text {eco }}$ /GPP ratio were fitted to generalised additive mixed effects models (see Methods). For GPP and $R_{\text {eco }}$ the effects of warming on median rates of ecosystem metabolism were larger in 2012 than in 2007. The $\mathrm{R}_{\mathrm{eco}} / \mathrm{GPP}$ ratio was higher in the warmed ponds and increased between 2007 and 2012. The solid lines denote the fixed effects from the best fitting GAMM model (see Table 2 for model selection). Red circles and lines denote warmed treatments, while the ambient treatments are in black. Box whisker plots of annual rates of (b) GPP, (d) $\mathrm{R}_{\text {eco, }}$ and (f) $\mathrm{R}_{\mathrm{eco}} / \mathrm{GPP}$ ratio from each pond calculated by integrating the seasonal data over time. Tops and bottoms of boxes in box-whisker plots correspond to the 25 th and 75 th percentiles, horizontal white lines correspond to medians, whisker extents correspond to $1.5 \mathrm{x}$ the interquartile range and blue points are outliers. 

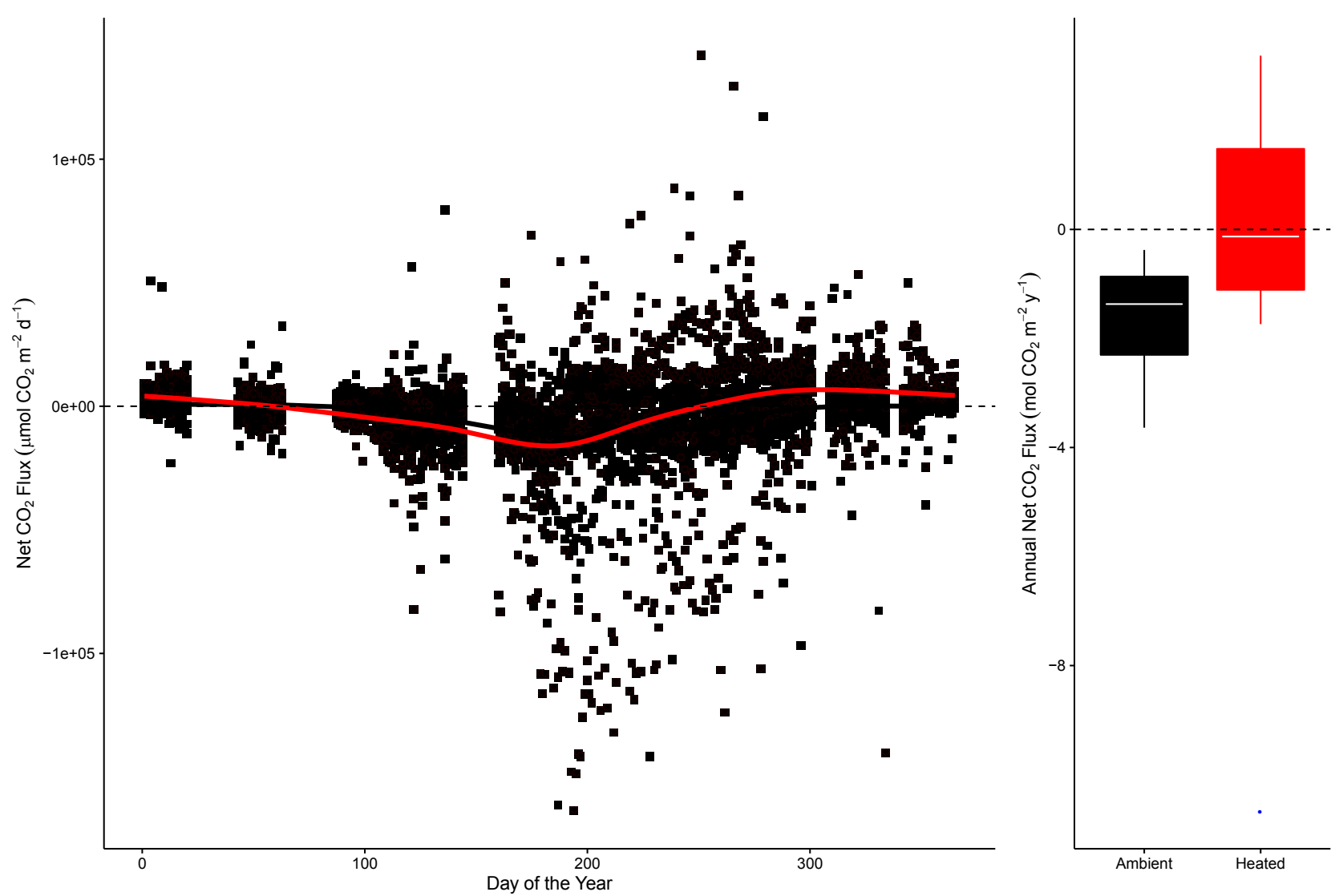

Figure 3| Experimental warming alters the phenology and annual budget of net $\mathrm{CO}_{2}$ flux. (a) Seasonal distribution of net $\mathrm{CO}_{2}$ flux data collected in 2013 reveal differences in the seasonality of net daily $\mathrm{CO}_{2}$ fluxes with maximal rates of net $\mathrm{CO}_{2}$ absorption peaking earlier in the year in the warmed treatments. The solid lines denote the fixed effects from the best fitting GAMM model. Red circles and lines denote warmed treatments, while the ambient treatments are in black. (b) Box whisker plot of the annual net $\mathrm{CO}_{2}$ fluxes calculated for each pond by integrating over the seasonal data reveal higher net fluxes in the warmed treatments (indicating lower $\mathrm{CO}_{2}$ absorption). Tops and bottoms of boxes in box-whisker plots correspond to the 25th and 75th percentiles, horizontal white lines correspond to medians, whisker extents correspond to $1.5 \mathrm{x}$ the interquartile range and blue points are outliers. 
290 The facility was established in 2005 and consists of 20 artificial ponds of approximately $1 \mathrm{~m}^{3}$ 291 volume, 50cm depth, sited in southern England (Freshwater Biological Association Rivers 292 Laboratory, East Stoke, $\left.2^{\circ} 10^{`} \mathrm{~W}, 50^{\circ} 13^{`} \mathrm{~N}\right)$, designed to be broadly representative of mid-latitude 293 shallow lakes ${ }^{10}$. Warming of $4-5^{\circ} \mathrm{C}$ above ambient began in half of the ponds in 2006 by 294 maintaining a constant differential between thermocouples in a pair of warmed and ambient ponds 295 (Fig. S1). The ponds contain well established benthic and pelagic communities including assemblages of macrophytes (Table S2), phytoplankton, algal biofilms and invertebrates; for a detailed description of the community composition see previous publications from this facility ${ }^{10,21,30}$. 298 Sediments are comprised of 8-10 cm of fine sands with a developed organic layer of 1-3 cm (Table $2992)$.

\section{Methane flux measurements}

$302 \mathrm{CH}_{4}$ fluxes were measured using a static, polythene-dome chamber $(0.5 \mathrm{~L})$ fitted with a foam collar and butyl septum ${ }^{31}$. Gas samples $(1 \mathrm{~mL})$ were withdrawn from the chamber through the septum 304 using a gas-tight syringe and transferred to a glass-vial (3 mL, Exetainer, Labco, UK) containing 305 helium-purged water. A single flux measurement on each pond was made by collecting samples at 306 five time-points over an hour just after sunrise. Samples of atmospheric air and water were also 307 collected immediately after each flux measurement and stored in the same way. All water samples 308 were fixed with mercuric chloride $\left(50 \mu \mathrm{L}\right.$ saturated solution) and stored at $4{ }^{\circ} \mathrm{C}$ before analysis. 309 Methane in the headspace of vials was measured by Gas Chromatography with a Flame Ionization Detector (GC-FID, Agilent Technologies, UK) ${ }^{32}$. The GC was calibrated using 0 and 100 ppm span 311 gases. The concentration of methane in the sample headspace was converted to in situ concentration 312 using the solubility coefficient of methane in water at analytical temperature ${ }^{33} . \mathrm{CH}_{4}$ efflux $\left(\mu \mathrm{mol} \mathrm{m} \mathrm{m}^{-}\right.$

\footnotetext{
${ }^{2} \mathrm{~d}^{-1}$ ) was calculated using linear regression of methane concentration in the chamber headspace $v s$
} 
314 time, taking the respective chamber volume and surface-area into account. In 2007-8, after one year

315 of experimental warming, $\mathrm{CH}_{4}$ fluxes were measured on 7 occasions over a year ${ }^{11}$. In 2013-14, after

316 seven years of warming, $\mathrm{CH}_{4}$ fluxes were measured on 12 occasions (2-6 weeks apart).

\section{Carbon dioxide flux measurements}

319 Carbon dioxide fluxes were measured over the annual cycle of 2013-14 using sixteen multiplexed 320 automatic gas flux chambers (LI8100 \& LI8150, Li-Cor) mounted on floating rings (Fig. S1c).

321 Because this system is limited to analysing 16 parallel ports, we deployed gas flux chambers on 8 of 322 the 10 heated and 8 of the 10 ambient replicate ponds and all analyses of the $\mathrm{CO}_{2}$ flux data focus on 323 this subset of the experiment. Acquisition frequency was $1 \mathrm{~Hz}$ and one flux measurement was 324 recorded from each pond hourly. The optical bench of the infra-red gas analyser was calibrated 325 using zero and 500 ppm span-gases (Spantech, UK). Fluxes of $\mathrm{CO}_{2}$ were estimated by linear 326 regression of the chamber $\mathrm{CO}_{2}$ concentration over time using standard Li-Cor software. Carbon 327 dioxide fluxes followed a regular diel pattern of emission during darkness followed by absorption 328 during daylight (Fig. S3). Trapezoidal integration was used to find the daily area under the efflux 329 and influx curves, and daily net exchange was calculated as the sum of daily influx and efflux.

\section{Ecosystem metabolism}

Rates of gross primary production (GPP) and ecosystem respiration $\left(\mathrm{R}_{\mathrm{eco}}\right)$ were measured over a

333 24h diel cycle for each replicate mesocosm on alternate months in 2007-08 and 2012-13 using the 334 free water dissolved oxygen (DO) change technique ${ }^{34}$. Measurements of DO and temperature were 335 taken every 15 minutes for 24 hours at mid-depth $(0.25 \mathrm{~m})$ in the water column of each pond with 336 YSI 600XLM multi-parameter Sondes, equipped with 6562 rapid pulse ${ }^{\mathrm{TM}}$ dissolved oxygen sensors. 337 Prior to deployment, the Sondes were calibrated in water-saturated air with a correction for 338 barometric pressure. Calibration accuracy was verified by monitoring the DO concentration of 339 water-saturated air for 10 minutes and checking against $100 \% \mathrm{O}_{2}$ saturation for the measured 
temperature and pressure. Measurements of DO, wind speed at $1.7 \mathrm{~m}$ (Cole-Parmer, WS-821), and

341 light intensity (Licor, LI-193) at mid-depth in the water column were used to calculate GPP and $342 \mathrm{R}_{\text {eco }}$ following the methods outlined in Staehr et $a l^{34}$ and using the equations given in Table S1.

\section{Temperature}

345 Water temperature was recorded automatically every 15 minutes by a temperature probe (TMC6346 HD Air/Soil/Water sensor, Onset, USA) and data-logger installed in each pond and additionally 347 checked on each visit to the facility with a YSI thermometer (Model 550A, YSI, USA). The 348 temperature of the warmed ponds averaged $4.8 \pm 1.0{ }^{\circ} \mathrm{C}$ higher than that of the ambient ponds over 349 the entire experiment.

\section{Sediment characteristics}

352 Sediment samples were collected in August 2013 using a $100 \mathrm{~mm}$ diameter corer (area $78.5 \mathrm{~cm}^{2}$ ). 353 Carbon and Nitrogen analysis of fine benthic organic matter $(<250 \mu \mathrm{m}$ particle size $)$ was conducted 354 using homogenized sediment that was acidified $(1 \mathrm{M} \mathrm{HCl})$ to remove carbonates ${ }^{35}$. The carbon and 355 nitrogen content of oven-dried $\left(60^{\circ} \mathrm{C}\right)$ samples was measured with an elemental analyzer (Integra, 356 Sercon UK). In-house certified reference materials were EMA P2 and Casein (Elemental 357 Microanalysis, UK). These materials were included during each batch of samples to check for accuracy and repeatability.

\section{Statistical analysis}

361 Rates of $\mathrm{CH}_{4}$ emissions, GPP and $\mathrm{R}_{\text {eco }}$ exhibited strong right-skew (e.g. high frequency of low rates 362 and few high rates) and were therefore natural-logarithm transformed prior to statistical analyses 363 and plotting. Net $\mathrm{CO}_{2}$ fluxes were normally distributed and were therefore left untransformed. We 364 used generalised additive mixed effects models (GAMMs) to characterise the phenology and overall treatment effects on rates of greenhouse gas emissions $\left(\mathrm{CH}_{4}\right.$ and $\mathrm{CO}_{2}$ fluxes $)$ and ecosystem 
metabolism (GPP and $\mathrm{R}_{\mathrm{eco}}$ ), to account for the hierarchical nature of our experimental data ${ }^{36}$. For

367 example, our experimental design yielded replicate seasonal responses for each rate in each treatment over two sampling years (2007 and 2012 [GPP and Reco] or 2013 [ $\mathrm{CH}_{4}$ and $\mathrm{CO}_{2}$ fluxes]). This hierarchical structure meant that rate measurements were non-independent - e.g. measurements from the same pond and sampling year are likely to be autocorrelated. We account

371 for this by treating sampling year nested within pond as a random effect on the intercept of the model which models deviations among ponds and years from the fixed effects as normally distributed with a mean of zero. The most complex models included a treatment by year interaction on the intercept (which characterises the median value of the response variable) and allowed the shape of the seasonal phenology, which was modelled using a cubic regression spline, to vary among treatments. Treatment effects on the shape and intercept of the seasonal phenology and year effects on the intercept were modeled as fixed effects in the GAMMs. Model selection entailed fitting a range of models to the rate data, starting with the full model and then a series of reduced models with interaction terms and main effects removed to test hypotheses about the potential differences in rates among treatments and sampling years. For multi-model selection we computed small sample-size corrected AIC scores (AICc) and then compared between models by calculating delta AICc values and AIC weights using the 'MuMIn' package. GAMMs were fitted to the data using the 'gamm4' package and all statistical analyses were conducted in R (v.3.23). We calculated the annual rates of greenhouse gas emissions $\left(\mathrm{CH}_{4}\right.$ and $\mathrm{CO}_{2}$ fluxes) and ecosystem metabolism (GPP and $\mathrm{R}_{\mathrm{eco}}$ ) for each pond on each year by exponentiation of the median natural log-transformed daily rate estimated from the mixed effects model and multiplying by 365 .

\section{Data availability}

The data that support the findings of this study are available from the corresponding author upon reasonable request. 


\section{References}

31. Bastviken, D., Ejlertsson, J. \& Tranvik, L. Measurement of methane oxidation in lakes: A comparison of methods. Environ. Sci. Technol. 36, 3354-3361 (2002).

32. Sanders, I. A. et al. Emission of methane from chalk streams has potential implications for agricultural practices. Freshwater Biology 52, 1176-1186 (2007).

33. Wilhelm, E., Battino, R. \& Wilcock, R. J. Low-pressure solubility of gases in liquid water. Chem. Rev. 77, 219-262 (1977).

34. Staehr, P. A. et al. Lake metabolism and the diel oxygen technique: State of the science. Limnol Oceanogr-Meth 8, 628-644 (2010).

35. Hedges, J. I. \& Stern, J. H. Carbon and nitrogen determinations of carbonate-containing solids. Limnol. Oceangr. 29, 657-663 (1984).

36. Zuur, A., Ieno, E., Walker, N. \& Saveliev, A. Mixed effects models and extensions in ecology with R. (Springer Verlag, 2009) 
406 